\title{
Scholarly Productivity and Rank in Academic Hospital Medicine
}

\author{
Andrew Sumarsono, MD ${ }^{1,2 \star}$, Neil Keshvani, MD ${ }^{1,3}$, Sameh N Saleh, MD $1,2,5$, Nathan Sumarsono, BS ${ }^{4}$, Mindy Tran, BS $^{6}$, \\ Maryam Warsi, MPH${ }^{2}$, Christiana Renner, MD ${ }^{1,2}$, Eugene S Chu, MD ${ }^{1,2}$
}

\begin{abstract}
1Department of Internal Medicine, University of Texas Southwestern Medical Center, Dallas, Texas; ${ }^{2}$ Division of Hospital Medicine, Parkland Memorial Hospital, Dallas, Texas; ${ }^{3}$ Division of Cardiology, University of Texas Southwestern Medical Center, Dallas, Texas; ${ }^{4}$ University of Texas Southwestern School of Medicine, Dallas, Texas; ${ }^{5}$ Clinical Informatics Center, University of Texas Southwestern Medical Center, Dallas, Texas; ${ }^{6}$ Columbia University Mailman School of Public Health, New York, New York.
\end{abstract}

Despite the rapid growth of academic hospital medicine, scholarly productivity remains poorly characterized. In this cross-sectional study, distribution of academic rank and scholarly output of academic hospital medicine faculty are described. We extracted data for 1554 hospitalists on faculty at the top 25 internal medicine residency programs. Only $11.7 \%$ of faculty had reached associate $(9.0 \%)$ or full professor (2.7\%). The median number of publications was 0.0 (interquartile range [IQR], 0.0-4.0), with $51.4 \%$ without a single publication. Faculty 6 to 10 years post residency had a median of 1.0 (IQR, 0.0-4.0) publication, with $46.8 \%$ of these faculty without a publication. Among men, $54.3 \%$ had published at least one manuscript, compared to $42.7 \%$ of women $(P<.0001)$. Predictors of promotion included $\mathrm{H}$-index, number of years post residency graduation, completion of chief residency, and graduation from a top 25 medical school. Promotion remains uncommon in academic hospital medicine, which may be partially due to low rates of scholarly productivity. Journal of Hospital Medicine 2021;16:545-548. (C) 2021 Society of Hospital Medicine
H ospital medicine has grown rapidly, with more than 50,000 hospitalists practicing nationally in $2016 .{ }^{1}$ Despite the remarkable increase in academic hospital medicine faculty (AHMF), scholarly productivity remains underdeveloped. Prior evidence suggests peerreviewed publications remain an important aspect of promotion in academic hospital medicine. ${ }^{2}$ However, there are multiple barriers to robust scholarly productivity among AHMF, including inadequate mentorship, ${ }^{3}$ lack of protected scholarship time ${ }^{4}$ and greater participation in nonclinical activities outside of peer-reviewed clinical research. ${ }^{5}$ Though research barriers have been described previously, the current state of scholarly productivity among AHMF has not been characterized. In this cross-sectional study, we describe the distribution of academic rank and scholarly output of a national sample of AHMF.

\section{METHODS}

\section{Study Design and Data Source}

We performed a cross-sectional study of AHMF at the top 25 internal medicine residency programs as determined by Doximity.com as of February 1, 2020 (Appendix Table 1). Between March and August 2020, two authors (NS, MT) visited

*Corresponding Author: Andrew Sumarsono, MD;

Email: Andrew.Sumarsono@utsouthwestern.edu; Telephone: 408-806-3976.

Drs Sumarsono and Keshvani are co-first authors.

Published online first June 16, 2021.

Find additional supporting information in the online version of this article.

Received: August 31, 2020; Revised: March 16, 2021; Accepted: March 30, 2021

(c) 2021 Society of Hospital Medicine DOI 10.12788/jhm.3631 each residency program's website, identified all faculty listed as members of the hospital medicine program, and extracted demographic data, including degrees, sex, residency, medical school, year of residency graduation, completion of chief residency, completion of fellowship, and rank. We categorized all academic titles into full professor, associate professor, assistant professor, and instructor/lecturer. Missing information was supplemented by searching state licensing websites and Doximity.com. Sex was validated using Genderize.io. We queried the Scopus database for each AHMF's name and affiliated institution to extract publications, citations, and $\mathrm{H}$-index (metric of productivity and impact, derived from the number of publications and their associated citations). ${ }^{6}$ We categorized medical schools by rank (top 25, top 50, or unranked), as defined by the 2020 US News Best Medical Schools, sorted by research ${ }^{7}$ and by location (United States, international Caribbean, and international non-Caribbean). We excluded programs without hospital medicine section/division webpages and AHMF with nonpromotion titles such as "adjunct professor" or "acting professor" or those with missing data that could not be identified using these methods.

\section{Analysis}

Summary statistics were generated using means with standard deviations and medians with interquartile ranges. We evaluated postresidency years 6 to 10 and 14 to 18 as conservative time frames for promotion to associate and full professor, respectively. These windows account for time spent for additional degrees, instructor years, and alternative career pathways. Demographic differences between academic ranks were determined using chi-square and Kruskal-Wallis analyses. 
TABLE. Cohort Demographics

\begin{tabular}{|c|c|c|c|c|c|c|}
\hline & $\begin{array}{c}\text { Instructor } \\
(n=471,30.3 \%)\end{array}$ & $\begin{array}{l}\text { Assistant professor } \\
(\mathrm{n}=901,58.0 \%)\end{array}$ & $\begin{array}{l}\text { Associate professor } \\
(\mathrm{n}=140,9.0 \%)\end{array}$ & $\begin{array}{l}\text { Full professor } \\
(n=42,2.7 \%)\end{array}$ & $\begin{array}{l}\text { Total cohort } \\
(\mathrm{N}=1,554)\end{array}$ & $P$ value \\
\hline Female, №. (\%) & $219(46.5)$ & $466(51.7)$ & $61(43.6)$ & $16(38.1)$ & $762(49.0)$ & 0.058 \\
\hline $\begin{array}{l}\text { Years since residency graduation, } \\
\text { median (IQR), y }\end{array}$ & $2.0(1.0-5.0)$ & $6.0(3.0-11.0)$ & $13.0(10.0-18.0)$ & $20.5(18.0-24.0)$ & $6.0(2.0-11.0)$ & $<.001$ \\
\hline \multicolumn{7}{|l|}{ Additional degrees, №. (\%) } \\
\hline Master's & $54(11.5)$ & $127(14.1)$ & $26(18.6)$ & $10(23.8)$ & $217(14.0)$ & 0.04 \\
\hline Doctorate & $12(2.5)$ & $27(3.0)$ & $7(5.0)$ & $3(7.1)$ & $49(3.2)$ & 0.22 \\
\hline Other & $0(0.0)$ & $1(0.1)$ & $1(0.7)$ & $0(0.0)$ & $2(0.1)$ & 0.22 \\
\hline $\begin{array}{l}\text { Graduation from international medical school, } \\
\text { No. (\%) }\end{array}$ & $72(15.3)$ & $219(24.3)$ & $15(10.7)$ & $1(2.4)$ & $307(19.8)$ & $<.001$ \\
\hline $\begin{array}{l}\text { Graduation from top } 25 \text { medical school, } \\
\text { No. (\%) }\end{array}$ & $161(34.2)$ & $265(29.4)$ & $69(49.3)$ & $24(57.1)$ & $519(33.4)$ & $<.001$ \\
\hline Completed chief residency, №. (\%) & $33(7.0)$ & $40(4.4)$ & $18(12.9)$ & $7(16.7)$ & $98(6.3)$ & $<.001$ \\
\hline Completed fellowship, №. (\%) & $29(6.2)$ & $111(12.3)$ & $26(18.6)$ & $10(23.8)$ & $176(11.3)$ & $<.001$ \\
\hline
\end{tabular}

Abbreviation: IQR, interquartile range.

Because promotion occurs sequentially, a proportional odds logistic regression model was used to evaluate the association of academic rank and $\mathrm{H}$-index, number of years post residency, completion of chief residency, graduation from a top 25 medical school, and sex. Since not all programs have the instructor/ lecturer rank, only assistant, associate, and full professors were included in this model. Significance was assessed with the likelihood ratio test. The proportional odds assumption was assessed using the score test. All adjusted odds ratios and their associated $95 \%$ confidence intervals were recorded. A two-tailed $P$ value $<.05$ was considered significant for this study, and SAS version 9.4 (SAS Institute Inc) was used to conduct all analyses. This study was approved by the UT Southwestern Institutional Review Board.

\section{RESULTS}

\section{Cohort Demographics}

Of the top 25 internal medicine programs, 3 were excluded because they did not have websites that listed AHMF. Of the remaining 22 programs, we identified 1829 AHMF. We excluded 166 AHMF because we could not identify title or year of residency graduation and 109 for having nonpromotion titles, leaving 1554 AHMF (Appendix Figure). The cohort characteristics are described in Table 1. The cohort was $49.0 \%$ female and included $42(2.7 \%)$ full professors, $140(9.0 \%)$ associate professors, 901 (58.0\%) assistant professors, and 471 (30.3\%) instructors/lecturers. Of these AHMF, $6.3 \%$ and $11.3 \%$ had completed a chief residency or fellowship, respectively; additional degrees were held by 268 (17.3\%), including 217 master's equivalent, 49 doctorates, and 2 others. Of these AHMF, $19.8 \%$ graduated from an international medical school, and $33.4 \%$ graduated from a top 25 medical school. When strati- fied by rank, the median years from residency completion was 2.0 for instructors, 6.0 for assistant professors, 13.0 for associate professors, and 20.5 for full professors (Figure).

\section{Research Productivity}

A total of 9809 documents had been published by this cohort of academic hospitalists (Appendix Table 2). Overall mean (SD) and median (IQR) publications were 6.3 (24.3) and 0.0 (0.0-4.0), respectively. A total of 799 (51.4\%) AHMF had no publications, 347 (22.3\%) had one to three publications, 209 (13.4\%) had 10 or more, and $39(2.5 \%)$ had 50 or more. The median number of publications stratified by academic rank were 0.0 (IQR, 0.01.0) for instructors, 0.0 (IQR, 0.0-3.0) for assistant professors, 8.0 (IQR, 2.0-23.0) for associate professors, and 38.0 (IQR, 6.0-99.0) for full professors. Among men, $54.3 \%$ had published at least one manuscript, compared to $42.7 \%$ of women $(P<.0001)$. The distribution of $\mathrm{H}$-indices by years since residency graduation is shown in the Figure. The median number of documents published by faculty 6 to 10 years post residency was 1.0 (IQR, 0.0-4.0), with $46.8 \%$ of these faculty without a publication. For faculty 14 to 18 years post residency, the median number of documents was 3.0 (IQR, 0.0-11.0), with $30.1 \%$ of these faculty without a publication. Years post residency and academic rank were correlated with higher $\mathrm{H}$-indices as well as more publications and citations $(P<.0001)$.

\section{Factors Associated With Academic Rank}

Factors associated with rank are described in Appendix Table 3. In our multivariable ordinal regression model, $\mathrm{H}$ index (adjusted odds ratio [aOR], 1.16 per single $\mathrm{H}$-index point; $95 \% \mathrm{Cl}, 1.12-1.20$ ), years post residency graduation 


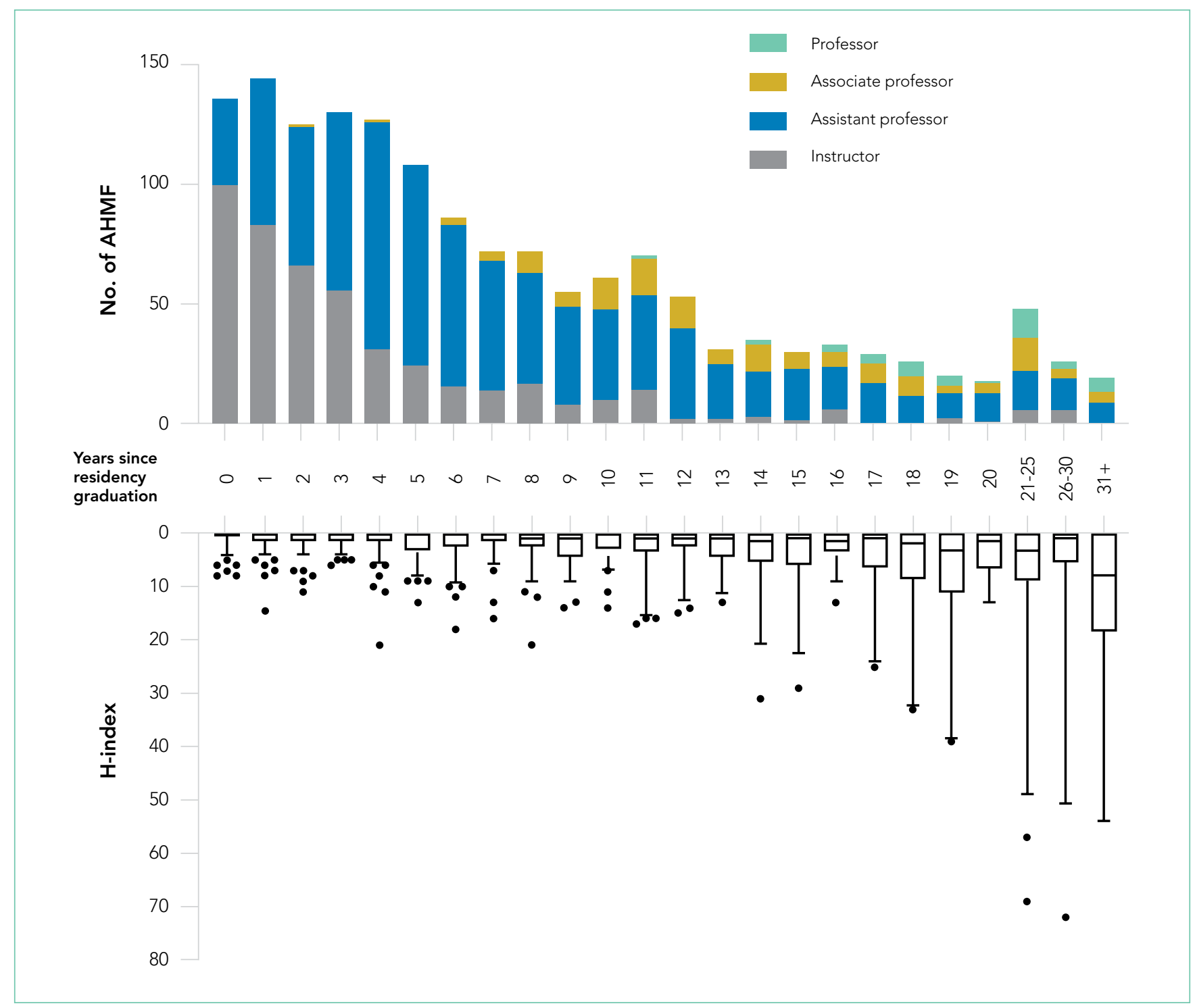

FIG. (A) Distribution of Academic Hospitalist Ranks and (B) Box-whisker Plot Distribution of H-index by Years Since Residency Graduation

(aOR, 1.14; $95 \% \mathrm{Cl}, 1.11-1.17)$, completion of chief residency (aOR, 2.46; 95\% Cl, 1.34-4.51), and graduation from a top 25 medical school (aOR, 2.10; 95\% Cl, 1.44-3.06) were associated with promotion.

\section{DISCUSSION}

In this cross-sectional analysis of more than $1500 \mathrm{AHMF}$ at the top 25 internal medicine residencies in the United States, $88.3 \%$ were instructors or assistant professors, while only $11.7 \%$ were associate or full professors. Furthermore, $51.4 \%$ were without a publication, and only $26.3 \%$ had published more than three manuscripts. Last, $\mathrm{H}$-index, completion of a chief residency, years post residency, and graduation from a top 25 medical school were associated with higher academic rank.

Only $2.7 \%$ of the cohort were full professors, and $9.0 \%$ were associate professors. In comparison, academic cardiology faculty are $28.2 \%$ full professors and $22.9 \%$ associate professors. ${ }^{8}$
While the field of hospital medicine is relatively new, many faculty members had practiced for the expected duration of time for promotion consideration, with assistant professors or instructors constituting $89.9 \%$ of faculty at 6 to 10 years and $63.6 \%$ of faculty at 14 to 18 years post residency. We additionally observed a gender gap in publication history in hospital medicine, consistent with prior studies in hospital medicine that suggested gender disparities in scholarship. 9,10 Increased focus will be needed in the future to ensure opportunities for scholarship are equitable for all faculty in hospital medicine.

Our findings suggest that scholarly productivity in academic hospital medicine remains a challenge. Prior studies have reported that less than half of academic hospitalists have ever published, and fewer than one in eight have received research funding. ${ }^{11,12}$ It is encouraging, however, that publications increase with time after residency. These data are consistent with the literature demonstrating a modest increase in 
hospitalists who had ever published, increasing from $43.0 \%$ in 2012 to $48.6 \%$ in $2020 .{ }^{12}$ Despite these trends, however, some early-career academic hospitalists report ambivalence toward academic productivity and promotion. ${ }^{13}$ Whether this ambivalence is the source of low scholarship output or the outcome of insufficient mentorship and limited research success is uncertain. But these factors, combined with the pressures of clinical productivity, the existing lack of mentorship, and inadequate protected research time represent barriers to successful scholarship in academic hospital medicine.,14

Our study has several limitations. First, our inclusion criteria for the top 25 internal medicine residencies may have excluded hospital medicine divisions with substantial scholarly productivity. However, with 21 of the 25 programs listed on Doximity.com in the top 25 for internal medicine research funding, it is likely that our results overestimate scholarly productivity if compared to a complete, national cohort of AHMF. ${ }^{15}$ Second, our findings may not be generalizable to hospitalists who practice in nonacademic settings. Third, we were unable to account for differences in promotion criteria/ tracks or scholarly output expectations between institutions. This limitation has been seen similarly in prior studies linking promotion and $\mathrm{H}$-index. ${ }^{2}$ Furthermore, our study does not capture promotion via other pathways that may not depend on scholarly output, such as hospital leadership roles. Last,

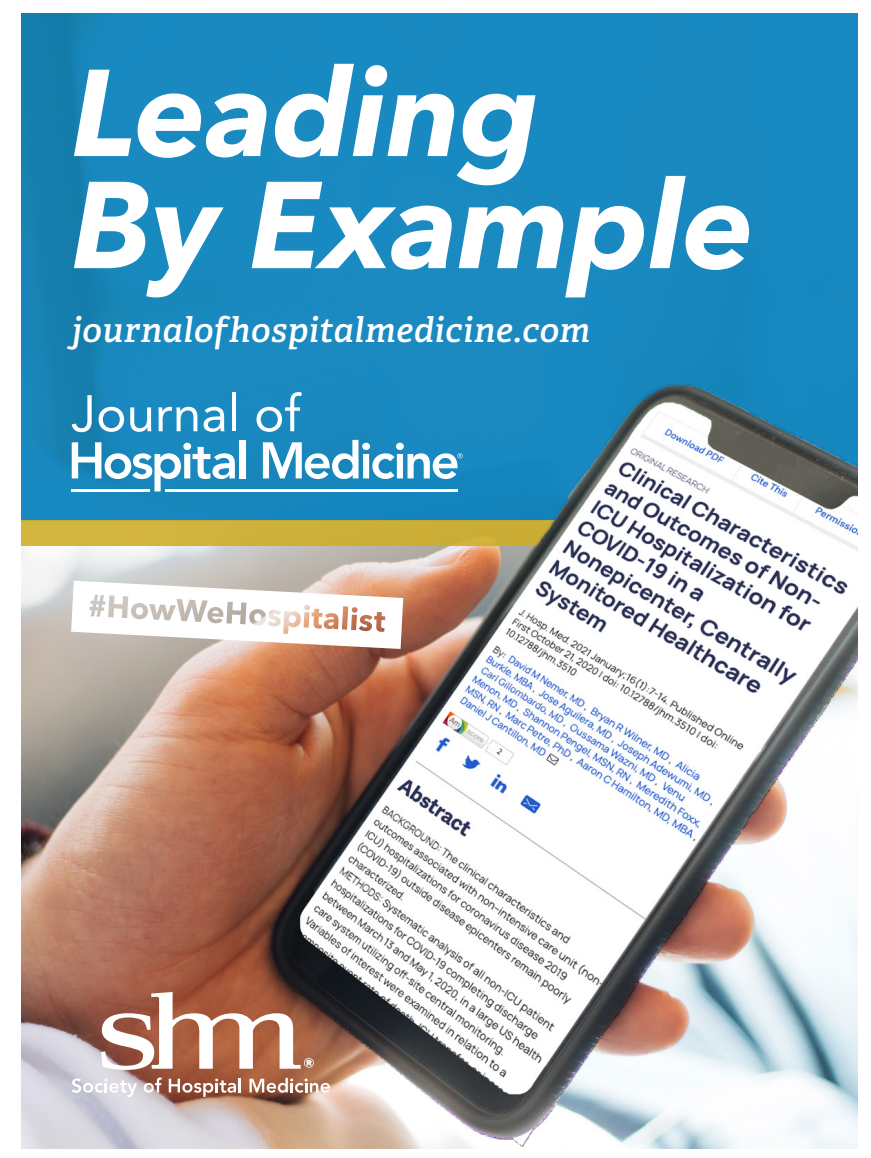

as data were abstracted from academic center websites, it is possible that not all information was accurate or updated. However, we randomly reevaluated $25 \%$ of hospital division webpages 6 months after our initial data collection and noted that all had been updated with new faculty and academic ranks, suggesting our data were accurate.

These data highlight that research productivity and academic promotion remain challenges in academic hospital medicine. Future studies may examine topics that include understanding pathways and milestones to promotion, reducing disparities in scholarship, and improving mentorship, protected time, and research funding in academic hospital medicine.

Disclosures: The authors reported no conflicts of interest.

\section{References}

1. Wachter RM, Goldman L. Zero to 50,000 - the 20th anniversary of the hospitalist. N Engl J Med. 2016;375(11):1009-1011. https://doi.org/10.1056/ NEJMp1607958

2. Leykum LK, Parekh VI, Sharpe B, Boonyasai RT, Centor RM. Tried and true: a survey of successfully promoted academic hospitalists. J Hosp Med. 2011;6(7):411-415. https://doi.org/10.1002/jhm.894

3. Harrison R, Hunter AJ, Sharpe B, Auerbach AD. Survey of US academic hospitalist leaders about mentorship and academic activities in hospitalist groups. J Hosp Med. 2011;6(1):5-9. https://doi.org/10.1002/jhm.836

4. Cumbler E, Rendón P, Yirdaw E, et al. Keys to career success: resources and barriers identified by early career academic hospitalists. J Gen Intern Med. 2018;33(5):588-589. https://doi.org/10.1007/s11606-018-4336-7

5. Flanders SA, Centor B, Weber V, McGinn T, DeSalvo K, Auerbach A. Challenges and opportunities in academic hospital medicine: report from the Academic Hospital Medicine Summit. J Hosp Med. 2009;4(4):240-246. https://doi.org/10.1002/jhm.497

6. Hirsch JE. An index to quantify an individual's scientific research output. Proc Natl Acad Sci U S A. 2005;102(46):16569-16572. https://doi.org/10.1073/ pnas.0507655102

7. 2021 Best Medical Schools: Research. U.S. News \& World Report. Accessed April 23, 2021. https://www.usnews.com/best-graduate-schools/topmedical-schools/research-rankings

8. Blumenthal DM, Olenski AR, Yeh RW, et al. Sex differences in faculty rank among academic cardiologists in the United States. Circulation. 2017;135(6):506-517. https://doi.org/10.1161/CIRCULATIONAHA.116.023520

9. Burden M, Frank MG, Keniston A, et al. Gender disparities in leadership and scholarly productivity of academic hospitalists. J Hosp Med. 2015;10(8):481-485. https://doi.org/10.1002/jhm.2340

10. Adler E, Hobbs A, Dhaliwal G, Babik JM. Gender differences in authorship of clinical problem-solving articles. J Hosp Med. 2020;15(8):475-478. https:// doi.org/10.12788/jhm.3465

11. Chopra V, Burden M, Jones CD, et al. State of research in adult hospital medicine: results of a national survey. J Hosp Med. 2019;14(4):207-211. https:// doi.org/10.12788/jhm.3136

12. Dang Do AN, Munchhof AM, Terry C, Emmett T, Kara A. Research and publication trends in hospital medicine. J Hosp Med. 2014;9(3):148-154. https:// doi.org/10.1002/jhm.2148

13. Cumbler E, Yirdaw E, Kneeland $P$, et al. What is career success for academic hospitalists? A qualitative analysis of early-career faculty perspectives. J Hosp Med. 2018;13(6):372-377. https://doi.org/10.12788/ jhm.2924

14. Reid MB, Misky GJ, Harrison RA, Sharpe B, Auerbach A, Glasheen JJ. Mentorship, productivity, and promotion among academic hospitalists. J Gen Intern Med. 2012;27(1):23-27. https://doi.org/10.1007/s11606-0111892-5

15. Roskoski R Jr, Parslow TG. Ranking tables of NIH funding to US medical schools in 2019. Accessed April 23, 2021. http://www.brimr.org/NIH_ Awards/2019/NIH_Awards_2019.htm 